\title{
Lola ReRuns in the Classroom: Dramatic Improvisations on the Film Run Lola Run for Intermediate German Instruction
}

\author{
Erika M. Nelson
}

\begin{abstract}
This paper presents an approach of how student-created dramatic reenactments and improvisational renditions of the German film Run Lola Run (Lola rennt, Tom Tykwer 1998) can serve as important vehicles to foster transcultural and communicative, student-centered competence in intermediate German language instruction, based on successful implementation in two intermediate college German courses. By performing improvised scenes, inspired by key scenes of the film, students learn to closely interpret and engage with the film's themes and motifs beyond the meta-textual level, while sharpening their mastery of situational vocabulary, cultural nuance, and linguistic structures of the German language. This film in particular, with its focus on repetition and variation, offers especially suitable material for facilitating students' awareness of language as a tool with which to access imaginative and interpretative potentials, as well as to express integral aspects of culture itself. The approach presented here also includes suggested materials, methods, and ideas to enhance understanding on the textual and performative levels and incorporate at the intermediate level of the curriculum, particularly for the Independent User level (B1 and B2) ${ }^{1}$ who has a basic grasp of the German language yet desires to develop greater linguistic flexibility and aptitude.
\end{abstract}

\section{Run Lola Run in the German Language Classroom}

Hip, visually-stunning and engaging, Tom Twyker's 1998 film Run Lola Run (Lola rennt) more than perhaps any other contemporary German film, helped break open the possibilities of incorporating film into German classrooms. As one of the most commercial and critically-acclaimed cinematic successes

1 The descriptors used in this article are employed by the Council on Europe's "Common Framework for Language Learning" and are similar to the ACTFL descriptors in intent and purpose. Independent User corresponds to Intermediate and is divided into B1 and B2. The full framework describing the various distinctions is available at $<$ http://www.coe.int/t/dg4/linguistic/CADRE $E_{E}$.asp $>$. 
from Germany in recent years, the film Run Lola Run catapulted Tykwer, along with the film's stars Franka Potente, who plays the fiery-redhead Lola, and Moritz Bleibtreu, who plays Lola's boyfriend Manni, into instant international stardom and the film into instant rotation in German-language classrooms around the world. This film's fast-paced, action-driven plot, energetic MTV-style visual aesthetics, popular soundtrack, and trendy protagonists are particularly appealing to students, as is the film's basic premise: it is part action thriller, part love story. Central to the plot is the idea of alternative realities and differently developed storylines, created by modifications of key elements, which in turn alter the outcome of the depicted events. The film is suitable for a variety of age groups and accessible to most levels of German language-learners. ${ }^{2}$

In second-language pedagogy, it is widely accepted that incorporating contemporary feature films into classroom instruction can be a valuable tool for offering meaningful cultural content that engages student interest and provides students with the opportunity to experience the target language and culture with a rare sense of immediacy and immersion in ways few other methodological tools can. Nevertheless, there remain many questions on how best to harness film's full potential in the classroom. All too often, films are simply screened in class, but not further discussed or didacticized in any constructive way, leading students to become passive viewers rather than active participants and learners. An added pitfall with film discussions in the classroom, as Rogers (2007: 172) has indicated, is an instructor's tendency to depend too exclusively on what he describes as "the framework of meta-talk" and characterizes as "an entire lesson built from the premise that students possess enough cultural knowledge and linguistic ability to focus exclusively on interpretation from the outset". Too much focus on such "interpretative talk about the content of a given film" often leads to a teacher-dominated class dynamic that frustrates intermediate-level students who lack the necessary tools to formulate opinions about the relevance of certain events depicted in the film and to speculate about inner motivations of the characters in the target language. As Peters suggests (2003: 123), language teachers often struggle "to convey sophisticated cultural knowledge to students who are intellectually mature but linguistically immature in the target language."

Given that Run Lola Run is so commonly taught in the German classroom, this paper suggests alternative ways of using this film as a model for students to imitate and build upon. Rather than viewing the film primarily as a text or cultural product to be discussed, interpreted, and analyzed in a content-based course, this paper presents a way to enable students to engage in independent spontaneous language use via dramatic improvisations based on key scenes of the film. Furthermore, this proposed approach offers a means to more fully integrate films into the pedagogical goals of the classroom through the introduction of specific drama techniques, ranging from simple role-playing activities to the performance of dramatic

\footnotetext{
${ }^{2}$ The film is also available with subtitles, if needed.
} 
renditions and improvisations, in order to develop communicative and cultural competencies, as well as active learning skills in students. In addition to incorporating culture at all levels, such an approach can help ensure that instruction continues to advance language competency.

Ample material and valuable resources already exist that are designed to support the teaching of this film, including pre-viewing, viewing, and post-viewing exercises structured to enhance student knowledge of vocabulary, cultural awareness and stimulate classroom discussion, foster essay writing skills, and test comprehension of the film, including for instance Chapter 3 in Borra and Mader-Koltay's book German Culture Through Film (2007) ${ }^{3}$ and materials included in German Culture Through Film: An Introduction to German Cinema (2005) and the accompanying workbook by Reimer, Zachau, and Sinka. Additional materials ${ }^{4}$ are also readily found on the internet, including such pertinent background material as a photographic tour of the shooting locales for the film. ${ }^{5}$ However, beyond the meta-textual aspects of approaching the film this article presents ideas that can easily complement the content-based teaching exercises these textbooks provide for the film and further tap the potential of this film for classroom purposes by offering a fun, imaginative means to deepen the learning experience and students' engagement with the film.

The proposed approach was implemented in two intermediate, i.e. second-year, German courses taught at the college level in the United States during the years 2005-2007 with observable success. Student interest, involvement, and participation noticeably increased with students dedicating more time and effort to this project, which they perceived as "fun", than to other assignments throughout the course of the year. Student feedback was overwhelmingly positive. Several students opted not only to perform their pieces but to produce a short film, not only of their scenes, but of the entire film, complete with several scene changes, props, and Lola's signature red hair.

As far as the assignment is concerned, the class participants were asked to work in small groups both in and outside the classroom to script their dramatized reenactments, which were then performed and presented to the entire class. Initially, students were given specific short key scenes to reenact, for instance, the beginning scene between Lola and Manni, or Lola and her father. Students were also asked to gloss any new or possibly unfamiliar terms on a handout to accompany their scenes. Following their performances, students engaged in a brief question and answer section, commenting and elaborating on the choices they introduced

\footnotetext{
3 A preview German Culture Through Film's Chapter 3 is available online at <http://yalepress.yale.edu/languages/pdf/BorraGerman_3.pdf>.

${ }^{4}$ Chapter 10 of the intermediate German language textbook Anders gedacht: Text and Context in the German-Speaking World (Motyl-Mudretzkyj/Späinghaus 2010), also features a thorough didactization of the film.

$5<$ http://german.about.com/library/bllolafotos.htm $>$.
} 
in their new versions.

\section{Film First and Foremost as Dramatic Text}

At the heart of this approach is the desire to foreground the underlying dramatic script of the story and bring it to life in all its various possible imaginative renditions. ${ }^{6}$ The cinematic version presents students with one possible dramatic rendition of the script. Other interpretations, of course, are possible. This point is best introduced before the actual screening of the film, by exposing students to parts of the script first. Short sections from key scenes, such as the example given below, can serve as helpful points of entry into the film, while also offering students the opportunity to begin to identify themselves as actors and engage with the story as a dramatic text: ${ }^{7}$

LOLA Manni?MANNI Mmh...LOLA Liebst du mich?MANNI Ja, sicher.LOLA Wie kannst du sicher sein?MANNI Bin's halt.LOLA Aber ich könnt auch irgend ne andere sein.MANNI Nee.LOLA Wieso nicht?MANNI Weil du die Beste bist.LOLA Die beste was?MANNI Na, die beste Frau.LOLA Von allen, allen Frauen?MANNI Na klar!LOLA Woher willst du das wissen?MANNI Das weiß ich halt.LOLA Du glaubst es.MANNI Gut, ich glaub's.LOLA Siehst du.MANNI Was?LOLA Du bist dir nicht sicher.MANNI Na, spinnst du jetzt oder was?LOLA Und wenn du mich nie getroffen hättest?MANNI Wie, was wär dann?LOLA Dann würdest du jetzt dasselbe einer anderen erzählen. MANNI Ich brauch's ja nicht zu sagen, wenn du's nicht hören willst.LOLA Ich will überhaupt nichts hören. Ich will wissen, was du fühlst.MANNI O.k., ich fühle, dass du die Beste bist.LOLA Dein Gefühl, wie ist denn das, dein Gefühl?MANNI Na ja, mein Herz.LOLA Dein Herz sagt, guten Tag Manni, die da, die ist es?MANNI Genau.LOLA Und du sagst, vielen Dank für die Information, aufWiederhören, bis zum nächsten Mal?MANNI Genau.LOLA Und du machst alles, was dein Herz dir sagt?MANNI Na, das sagt ja nichts, also, ja was weiß ich, das, ... es fühlt halt.LOLA Und, was fühlt es jetzt?MANNI Es fühlt, dass da gerade jemand ziemlich blöde Fragen stellt.LOLA Mann, du nimmst mich überhaupt nicht ernst.MANNI Lola, was ist denn los? Willst du irgendwie weg von mir?LOLA Ich weiß nicht, ich muss mich halt entscheiden, glaub ich. ${ }^{8}$ Little explanation is required to set up this scene as a commonly understood love scene, where one lover ask the other for reassurance of their love and devotion. Following clarification on new vocabulary items (or glossed scripts might prove more useful in this situation),

6 Tykwer's film Run Lola Run is the focus for this study. However, it is conceivable that other contemporary German films, including for instance, Die fetten Jahre sind vorbei or Das Wunder von Bern, to name but two of many, might also offer a route into similar cross-cultural understanding and interaction.

7 The complete script of the film is available for purchase Lola rennt: Das Buch zum Film (Berlin: Rowohlt, 1998), as well as an interview with the director Tom Tykwer.

8 An English translation of this passage is available as "Scene A" in the Appendix section. 
which ensures that students understand the content and context of the scene, one can begin to change the tone and nuances of the scene. For instance, altering the setting of the scene can dramatically change the delivery of the lines. What if, for instance, Lola and Manni are speaking on the phone, at a party, or in a crowded bus? What if Manni is with a different woman? Students can quickly approach the scene with their own interpretations and nuanced dramatic renditions. Encouraging students not only to read but to act out the scene, thereby forcing them to make decisions about the physicality of the scene and the characters' movements, fosters understanding of the importance of corporeal and verbal semiotics in performance. Prompting students by asking questions about each character and possible subtexts (e.g. What is Lola asking (for) in this scene? How and why is she asking these questions? Is it in jest? Out of concern? Out of insecurity or jealousy? Just because?) allows students to more fully explore each character through their own words, as well as the potential interpretations of the scene in order to better understand the interaction depicted in this scene. These early "performances" of the text enable students to engage directly with the text, fostering their ability to "read" the film as mutable text, rather than simply as scripted entertainment.

The conversational scenes from the film script also enable specific focus to be placed on developing the rhythm, modulation, and speed of spoken German, particularly as it is encountered in everyday conversation and slang. In this case, previewing this scene from the film, especially when repeated with and then without subtitles, can be useful in developing listening comprehension. Even though little evidence seems to support that oral reading and text memorization assist students with language mastery and pronunciation, ${ }^{9}$ the initial performances of these texts nonetheless aid students in gaining familiarity with the text. Once they view the film in its entirety, students undoubtedly recognize the scene and pay particular attention to the choices the actors made in dramatizing the scene and how the scene fits in within the social and cultural context of the film. Thus, the initial performances of these scenes serve to foster key intercultural skills identified by Dyskstra-Prium (2008: 74) as the "ability to interact appropriately with people from another country and culture in a foreign language, in a way which demonstrates an awareness of the specific meaning, connotations, and the historical and social context of the target language."

These initial performances of the script are best followed with a thorough screening, analysis, and discussion of the film with specific attention paid to the cyclical nature of the plot, as well as to the

\footnotetext{
${ }^{9}$ Bernhardt (1983:114) specifically addresses the lack of empirical evidence for oral reading's positive effect on pronunciation in her article "Three Approaches to Reading Comprehension in Intermediate German" while Kramsch (1983: 437) describes the trend away from rote learning as a pedagogical device in language acquisition.
} 
new and more sophisticated lexical items and elements of grammar. In the initial stages of the teaching unit, students focus specifically on linguistic and analytical comprehension of the film as text. It is highly recommended to provide students with a basic glossary for the film's first performed scene, as well as for the rest of the film, from which class participants can create subsets of key vocabulary targeted for active acquisition. ${ }^{10}$

A useful homework assignment includes instructing students to work in pairs and significantly alter the tone and mood of the scene by changing the characters' subtexts and the setting of the scene. Classroom participants who completed this exercise as part of classroom assignments in the past found that they particularly liked to choose their own subtexts for their characters, as well as the settings rather than being assigned them. It became somewhat of a guessing game. In class, each student pair is then asked to perform the scene without overtly revealing the chosen subtexts or the settings of the scene. Students in the audience then guess what the context is and describe the differences they note from the students' actual performances of the scene. When choices are not obvious or communicated clearly, students are then asked to offer other possible choices and performance alternatives in order to make these changes more readily understood.

\section{Why Lola? Why Reruns? The Structure of the Story}

Tom Tykwer's film Run Lola Run lends itself particularly well to reenactments and retellings, as the film thematizes the experience of time-shifting, parallel realities, and alternative versions. The story is subdivided into three different "takes," based on Lola's successive "runs." Each of Lola's runs presents various enactments, repetitions and variations. Associated with each of Lola's "runs" is a highly concentrated array of recurring visual cues and structural motifs that introduce a life-or-death moment into the plot, thereby intermingling seemingly unimportant reflections with larger questions of fate and determinism, contingency or volition, all somehow involving the two main protagonists, a homeless bum, and "die Tasche," the bag of money Manni loses.

The film begins as Lola receives a frantic call from her boyfriend Manni who has mistakenly left a bag full of DM 100,000 belonging to his mobster boss Ronnie in a subway car, where it was picked up by the homeless bum. Manni explains that if he does not show up at noon with the money (i.e. within 20 minutes), Ronnie will kill him. Panicked, he begs Lola for help. Lola then springs into action and takes of running in order to try and help Manni find the money and fulfill his obligations

\footnotetext{
${ }^{10}$ Each student can then contribute at least a half a dozen more items from the film that are not yet included in the glossary to the collective class list for personal learning.
} 
before the deadline. In three different versions or "runs", she finds three different potential solutions to the situation.

The film Run Lola Run follows the well-defined three-act structure with a clear time constraint and purpose: the film shows three attempts and each act corresponds exactly to the twenty minutes Lola has to find the missing money and save Manni. Each act begins at the moment Lola takes off running and thus presents one possible scenario that ends with a decisive victory or defeat in resolving the conflicts. In each run, some aspects and plot elements remain unchanged: for instance Lola encounters the same people, vehicles, and objects but experiences them differently according to the choices she makes. These include among others, a boy and a dog on the stairs of her apartment, a woman with a baby carriage, a group of nuns, a man riding his bike, a security guard at her father's bank, a blind woman, an ambulance, and men crossing the street with a large pane of glass. Lola attempts to acquire the money in different ways in each run, and the outcomes of the runs are dramatically different. Twice Lola and Manni are able to produce the money but in the each of the first two takes, one of them dies. Lola's last run finally resolves both aspects of the conflict in a Hollywood-style happy end.

From the very beginning the film introduces the metaphor of a game and encourages strategic thinking towards higher-end goals and solutions. Foss et al. (2007: 205) suggest the film offers an "understanding of agency," as Lola is able to "explicate three agentic orientations - victim, supplicant, and direction - each with a different interpretation of structure, a different response to that interpretation, and a different outcome." The various choices she makes determine her actions, which in turn generate different outcomes in an unending chain of causality. Students can imbibe these differences viscerally through the performance by improvising different variations on one scene (e.g. by inverting scenes, changing perspectives, characters, or choices in a scene, etc.), as well as intellectually through discussions. The potential for students to better understand their own sense of agency through performance is not ruled out. As Whalen (2000: 8) asserts, "like Lola, we, too, if we work at it, can become the player rather than the played" or as Lauer (2003: 8) suggests the film offers a "multiplicity of options constantly and joyfully different (and deferred) in a continuously evolving universe."

\section{Using the Film as Springboard to Set Up the Scene}

Students are asked to view the film in order to better understand the context and background of the film and to familiarize themselves with the plotline and content. Following the collective screening and initial discussions of the film, students can return to the initial scene they enacted and speak to differences they notice. Once students are able 
to handle structured group work incorporating dramatic techniques with some confidence, they are ready to take on imaginative activities that incorporate intellectually challenging, problem-solving issues that foster greater interaction and divergent thinking. At this point students can begin to develop their own variations on the film through dramatic role-paying and rewriting of the script. The first step requires that students begin with a short part of the script and write their own version of the key problem Manni faces.

The following scene, for instance, exemplifies such an instance, which can be used as a springboard for the rewriting of a scene that can later be developed into a larger and longer project. This passage introduces the audience to both the crisis situation and the time constraint. It begins with Lola's scream, followed by Lola's attempts to reassure Manni:

LOLA Du hörst mir jetzt zu. Du wartest da. Ich komme. Ich helf dir. Du bewegst dich nicht vom Fleck. Ich bin in zwanzig Minuten da. Kapiert?mAnNI Ach ja? Was willst du denn machen? Deine Juwelen verpfänden?LOLA Wo bist du?MANNI Na, in ner Zelle, Innenstadt ... bei der "Spirale".LOLA Alles klar. Bleib, wo du bist. Mir fällt was ein. Ich schwör es. Zwanzig Minuten, okay? ${ }^{11}$ Careful comprehension of the text requires that students incorporate a few apparent and important details into their responses, such as Lola's references to the time constraint and Manni's indication that he is under pressure, desperately needs Lola's help, and that he is in the city.

When beginning their improvised scenes inspired by the film, students need to make certain key decisions about the crisis. What sort of crisis does Manni face? They must then describe the situation, define the problem, and the constraints, i.e. the equivalent of Run Lola Run's "20 minutes to get the money and save Manni." Students can carry over some, but not all of the themes from the original film, and should make up the rest on their own. Situations should be kept simple and relatable with clear constraints, such as time restriction, lack of money, or a strict prohibition, and a sense of what needs to occur for the problem to be resolved. For this exercise, it might be most useful to eliminate the line about pawning her jewelry, thereby opening up the possibilities of the circumstances with which Manni requires Lola's help. Students are free to create an alternative background story and scene that incorporates this exchange between Manni and Lola. Perhaps it is not money that Manni needs, but some kind of important paperwork, or tickets. Maybe Manni has just been in an accident with his father's car, or his best friend's car has been towed. It could be that he has found a much-desired object he wishes to purchase but has forgotten his wallet. Perhaps, for instance, the film's "life-or-death moment" as interpreted from a student's perspective translates into the need to finish a final paper

\footnotetext{
${ }^{11}$ An English translation of this dialogue from the film is provided in the Appendix under the heading "Scene B."
} 
at the very last moment possible, with all types of possible distractions occurring unexpectedly. Or perhaps he has simply forgotten his final paper at home and needs to turn it in to the professor by a specific deadline. It is also important to stress that this scene will form the basis for other scenes, so the situation needs to portray a believable need, a relatable crisis of some sort that will sustain students' interest. When students are given enough time and encouragement with this segment, the results can often offer surprising and clever twists and turns in students' depiction of this iconic scene from the film.

Using the script as inspiration for alternative versions offers cognitive and affective benefits of dramatic role-playing in the classroom, as well as a rich opportunity to acquire new vocabulary and structures, fulfill sophisticated writing tasks and interact with others in realistic discourse situations. Linguistic targets for these exercises include advanced vocabulary building and structural acquisition. The fluidity and cyclical nature of the film's plot encourages variation and as such, stimulates imaginative responses and improvisations. Parts of the dialogs repeat three times in the film, giving viewers a particularly intimate sense of knowing the main character Lola's innermost thoughts. Through this identification with Lola, viewers find themselves actively involved in pondering possible alternative solutions. Adding the dimension of dramatic reenactments and improvisations takes such identification one step further, by engaging them corporeally. Performance of various scenarios from the film present students with opportunities to realize within spoken and embodied language the dilemma Lola faces first hand. They see the text from the inside out, peer inside a character, discover hidden motivations, as well as a felt-sense of urgency. As Sosulski (2008:1) asserts, dramatic renditions of the various scenes offers students the opportunity to "think both locally (about character and motive) and globally (about constellation and plot)." In this scene in particular, students learn to express urgency and necessity, as well as use persuasive techniques of bargaining. It also allows them to imagine a situation that requires immediate attention. These scenes can become stepping-stones to the larger classroom projects. as described in the next section.

\section{Scene Assignment: Structuring the Script and Writing the Reruns}

A longer project, related to the film and to the previously introduced exercise on re-writing the crisis situation from section 4, involves asking students to develop, act, and direct three individual, yet related scenes. For this project, students work together in small groups to expand their crisis scene, developed in section 4, and write a variation of the film, incorporating three short interrelated "runs" or scenes, the first two of which should be seen as failed attempts at reaching 
the desired outcome. The scenes need not be lengthy or difficult. Prior familiarity with the shorter scenes can aid students in gauging how much can be expressed in a few lines. It is best to offer clear directions to the students, with clear expectation of certain criteria.

As preparation, students should define what the successful, desired outcome is. For instance in the case of the final paper, a successful outcome might involve finishing the paper or turning the final paper in on time to the professor and meeting the deadline. In terms of the borrowed car that has been towed, it might translate into returning the car to the friend without any incident. Next the students should incorporate one or two obstacles or thwarted attempts, directly related to some aspect of their desired outcome and/or the constraint. These might involve something unexpected that emerges in the surrounding environment, a person, place, or event or certain routines, traditions, and limitations. once students have determined these issues, they can begin collaborating on the scenes and work toward the final outcome. True to the film, students might also try to incorporate small but potentially significant details in the narrative.

The instructor is asked to set up the classroom activity, clarify any issues, and then withdraw, thereby giving students the time and responsibility for their work. It is advisable to look over early drafts and work with students to correct linguistic mistakes, so as to eliminate them from final projects.

Ideally, students will wish to return to the film for inspiration, thereby learning an enhanced way of using film in foreign language instruction, that is they learn to work with film, not simply view it once. Such engagement with the film and the rewriting process challenges students to think imaginatively, draw on what they know, encourage them to learn what they do not yet know, work collaboratively with others, and generate meaningful dialogues that are then performed. The added task of addressing and resolving a deliberately ambiguous and difficult problem that demands they work from the known to the unknown often compels students to want to participate, contribute, and speak. Students are encouraged to learn their parts or practice ad-libbing. Brief reflective essays examining acting and directing choices can help clarify choices students have made and be included in the assignment. Students might also chose to film their film versions and make mini-movies to share with the class or upload it to a blog or website.

\section{Conclusions}

As dramatic material, films, especially Tykwer's film Run Lola Run, can offer unique access to imaginative retellings and performative improvisations in the foreign language classroom that develop a deeper level of cross-cultural understanding and interaction. Through simulated role-playing of the 
film scripts and imaginative recreations of variations on the script, students are able to more or less replicate true-to-life experiences that students might encounter in the target culture, such as trying to find solutions to problems they might face. This approach and these exercises were developed and introduced in intermediate German classrooms and were well received. When asked to provide feedback on the project, students spoke of the fun they had working with other students to create a significant project. Several students liked the "workshop" aspect of the project; while others felt it was a better use of time spent developing language skills. For instance, one student stressed, "I felt there were certain things I wanted my character to say, and I had to learn to say them." Students also felt more engaged and called upon to participate, not only as actors and writers, but also as audience members, understanding that their involvement was the key to their and other students' successful performances. Students became more creatively engaged learners and producers of the target language and actively worked collaboratively to create memorable performances and projects.

one challenge was to ensure that students worked toward grammatical accuracy, in addition to fluency. Requiring drafts and working with correcting and clarifying grammatical concerns in these early drafts proved to be an important step that needed to be introduced into the project after the first attempts of introducing this into the classroom.

The students' involvement with the film also increased their understanding of the themes, mechanics, and structure of the film. Students began to view the film through the lens of writers, actors, and producers and not simply as an audience member. The film became a sort of "edutainment," not simply entertainment.

In summary, drama in classroom thus offers a highly productive method of effectively achieving foreign language goals that incorporate inventiveness and reflective choice and encourage speakers to develop maneuverability within various speech situations, and ultimately where one must communicate in order to make things happen.

\section{Bibliography}

Arndt, Stefan (Producer); Twyker, Tom (Writer-Director): Run Lola Run (Lola rennt, 1998) [Film]

Berman, S. J. (1990): "Edutainment, an Idea Whose Time Has Come." In: The Language Teacher, 14/11: 11-13

Bernhardt, Elizabeth B. (1983): "Three Approaches to Reading Comprehension in Intermediate German." In: Modern Language Journal 67/2: 111-115

Bolton, Gavin (1984): Drama as Education. An Argument for Placing Drama at the Centre of the Curriculum. Harlow: Longman 
Borra, Adriana, and Mader-Koltay, Ruth (2007): German Through Film. New Haven: Yale University Press

Bräuer, Gerd (ed.): Body and Language: Intercultural Learning Through Drama. Advances in Foreign and Second Language Pedagogy. Vol. 3. Westport, CT: Ablex Publishing

Dykstra-Pruim, Pennylyn (2008): "Developing an Intercultural Curriculum: Challenges and Lessons Learned." In: Schulz, Renate \& Tschirner, Erwin (eds.): Communicating Across Borders: Developing Intercultural Competence in German as a Foreign Language. Munich: Iudicium, 71-87

Haase, Christine (2003): "You Can Run, but You Can't Hide: Transcultural Filmmaking in Run Lola Run (1998)." In: McCarthy, Margaret: Light Motives: German Popular Film in Perspective. Detroit: Wayne State University Press, 395-416

Foss, Sonja K.; Waters, William J.C.; Armada, Bernard J. (2007): "Toward a Theory of Agentic Orientation: Rhetoric and Agency in Run Lola Run." In: Communication Theory 17: 205-230

Lauer, A. Robert. (2003). "Run Lola Run at the Dawn of Postmodernity." In: Studies in Media and Information Literacy Education, 3/1: http://www.utpress.utoronto.ca/journal.ejournals/simile

Kramsch, Claire (1983): "Culture and Constructs: Communicating Attitudes and Values in the Foreign Language Classroom." In: Foreign Language Annals 16/6: 437-448

Motyl-Mudretzkyj, Irene; Michaela Späinghaus (2010): Anders Gedacht: Text and Context in the German-Speaking World. Heinle Cengage: Boston.

Peters, George (2003): "Integrating Culture in Beginning German. Kulturexkurse: A Model for Teaching Deeper German Culture in a Proficiency-Base Curriculum." In: Die Unterrichtspraxis/Teaching German 36/2: 121-134

Reimer, Robert; Zachau, Reinhard; Sinka, Margit (2005): German Culture Through Film: An Introduction to German Cinema. Focus: Newburyport, MA

Reimer, Robert; Zachau, Reinhard (2006): Arbeitsbuch zu German Culture Through Film. Focus: Newburyport, MA

Rogers, Jeff (2007): "Am Beispiel 'Anatomie': A Proficiency-Oriented Approach to Film for First- and Second-Year German." In: Die Unterrichtspraxis/Teaching German 40/2: $171-182$

Sosulski, Michael J. (2008): "Workshop in German Drama: Using Period Acting Techniques to Enhance Second Language Acquisition" Scenario 1/1, 7-16 
Erika M. Nelson

Lola ReRuns in the Classroom: Dramatic Improvisations on the Film Run Lola Run for Intermediate German Instruction

Whalen, Tom (2000): "The Rules of the Fame: Tom Twyker's Lola Rennt." In: Film Quarterly, 53/3: 33-40 


\section{Appendix}

\section{Scene A}

LOLA Manni?MANNI Hmm...LOLA Do you love me?MANNI Sure, I do. LOLA How can you be so sure?MANNI I don't know. I just am.LOLA I could be some other girl.MANNI No.LOLA Why not?MANNI Because you're the best. LOLA The best what?MANNI The best girl.LOLA of all the girls in the world?MANNI Sure!LOLA How do you know?MANNI I just do.LOLA You think so.MANNI Okay, I think so.LOLA You see.MANNI What?LOLA You aren't sure.MANNI Are you nuts or what?LOLA What if you never met me?MANNI what do you mean?LOLA You'd be telling the same thing to someone else.MANNI Okay, if you don't want to hear it.LOLA I don't want to hear anything. I want to know how you feel.MANNI Okay, my feelings say you're the best.LOLA Who is "your feelings" anyway?MANNI It's me. My heart.LOLA Your heart says, "Hi, Manni. She's the one." MANNI Exactly.LOLA And you say "Thanks for the information. See you around. "MANNI Exactly.LOLA And you do whatever your heart says?MANNI Well, it doesn't really "say" anything ... I don't know. It just feels.LOLA And what does it feel now?MANNI That someone's asking rather stupid questions. LOLA Man, you aren't taking me seriously.MANNI Lola, what's wrong? You want to leave me?LOLA Ich don't know. I just have to decide, I think. Scene $B$

LOLA Listen. Wait for me. I'll help you. Stay put. I'll be there in 20 minutes. Okay?MANNI Gonna pawn all your jewelry?LOLA Where are you?MANNI In a phone booth, downtown, in front of the Spirale Bar.LOLA. Okay, stay where you are. I promise I'll come up with something. 